\title{
Pengetahuan Perawat Tentang Perawatan Luka Metode Moist Wound Healing Di Rs Pmi Aceh Utara
}

\author{
Humaira $^{1}$, Mursal $^{2}$, Abrar $^{3}$ \\ ${ }^{1}$ Mahasiswa STIKes Muhammadiyah Lhokseumawe \\ ${ }^{2}$ Dosen Profesi Ners STIKes Muhammadiyah Lhokseumawe \\ ${ }^{3}$ Dosen Ilmu Keperawatan STIKes Muhammadiyah Lhokseumawe \\ *Correspondence : humaira97aira@gmail.com
}

\begin{abstract}
Wounds are damage to the integrity of the skin caused by many things such as friction, trauma, temperature, infection and others. The incidence of injuries is increasing every year, both either acute or chronic wounds. A recent research in America showed the prevalence of patients with wounds was 3.50 per 1000 population. The majority of wounds often occurred on the people in the world were caused by surgery / trauma $(48.00 \%)$, leg ulcers $(28.00 \%)$ and pressure sores $(21.00 \%)$. Moist wound healing is the latest method which is effective in healing wounds. The objective of this research was to know the level of knowledge of nurses about wound care by using the moist wound healing method at the Hospital of PMI, Aceh Utara Regency. This research design was descriptive using 60 people as population and 36 people as samples. The sampling was taken through a purposive sampling technique and it was the technique selected with specified criteria where the researcher selected 36 respondents as the samples. This research was conducted at the Hospital of PMI, Aceh Utara Regency using a questionnaire sheets. The statistical analysis used in this research was univariate analysis. Based on the results of the research, it showed that 19 respondents $(52.8 \%)$ had sufficient knowledge and 11 respondents (30.6\%) had insufficient knowledge. This data showed that the majority of respondents who had sufficient and insufficient knowledge. It is recommended that the Hospital of PMI, Aceh Utara can give facilitation and training of wound care for nurses so that the knowledge and skills of nurses will be better which has an impact on improving the quality of nursing care.
\end{abstract}

Key words : The Knowledge of Nurses, Wound care, Moist Wound Healing

\begin{abstract}
ABSTRAK
Luka merupakan kerusakan integritas kulit yang disebabkan oleh banyak hal seperti gesekan, trauma, suhu, infeksi dan lainnya. Angka kejadian luka setiap tahun semakin meningkat, baik luka akut maupun luka kronis. Sebuah penelitian terbaru di Amerika menunjukkan prevalensi pasien dengan luka adalah 3.50 per 1000 populasi penduduk. Mayoritas luka pada penduduk dunia adalah luka karena pembedahan/trauma (48.00\%), ulkus kaki (28.00\%), luka dekubitus $(21.00 \%)$. Moist wound healing merupakan metode terkini yang efektif menyembuhkan luka. Tujuan untuk mengetahui tingkat pengetahuan perawat tentang perawatan luka metode moist wound healing. Penelitian ini bersifat deskriptif dengan jumlah populasi 60 orang dan jumlah sampel 36 orang dengan teknik pengambilan sampel secara purposive sampling yaitu teknik pengmbilan sampel dengan kriteria yang ditentukan sebanyak 36 responden. Penelitian ini dilakukan di RS PMI Aceh Utara dengan menggunakan lembar kuisioner. Analisa statistik yang digunakan adalah analisa univariat. Hasil penelitian menunjukkan sebanyak 19 responden $(52,8 \%)$ memiliki pengetahuan yang cukup dan 11 responden $(30,6 \%)$ memiliki pengetahuan kurang. Data tersebut menunjukkan mayoritas responden memiliki pengetahuan yang cukup dan kurang. Disarankan bagi pihak RS agar dapat menfasilitasi pealtihan perawatan luka bagi perawat sehingga pebgetahuan dan ketrampilan perawat menjadi lebih baik yang berdampak pada peningkatan kualitas asuhan keperawatan.
\end{abstract}

Kata Kunci : Pengetahuan Perawat, Perawatan Luka, Moist Wound Healing 


\section{PENDAHULUAN}

Luka merupakan gangguan integritas kulit yang disebabkan oleh banyak hal, diantaranya gesekan, tekanan, suhu, infeksi dan lain-lain (Aristanty, 2012). Angka kejadian luka setiap tahun semakin meningkat, baik luka akut maupun luka kronis. Sebuah penelitian terbaru di Amerika menunjukkan prevalensi pasien dengan luka adalah 3.50 per 1000 populasi penduduk. Mayoritas luka pada penduduk duniacadalah luka karena pembedahan / trauma (48.00\%), ulkus kaki (28.00\%), luka dekubitus (21.00\%). Pada tahun 2009, MedMarket Diligence, sebuah asosiasi luka di Amerika melakukan penelitian tentang insiden luka di dunia berdasarkan etiologi penyakit. Diperoleh data untuk luka bedah ada 110.30 juta kasus, luka trauma 1.60 juta kasus,luka lecet ada 20.40 juta kasus, luka bakar 10 juta kasus, ulkus dekubitus 8.50 juta kasus, ulkus vena 12.50 juta kasus, ulkus diabetik 13.50 juta kasus, amputasi 0.20 juta pertahun, karsinoma 0.60 juta pertahun, melanoma 0.10 juta, komplikasi kanker kulit ada sebanyak 0.10 juta kasus (Wound West, 2013).

Dalam melakukan perawatan luka yang tepat diperlukan keterampilan perawat, sesuai dengan perkembangan ilmu pengetahuan dan teknologi (Potter dan Perry, 2009 dalam Naralia T, 2015). Penanganan yang tepat pada luka akut dan kronis bertujuan agar tidak jatuh kepada kondisi komplikasi seperti infeksi dan akhirnya memperlama waktu penyembuhan luka serta mencegah terjadinya keparahan yang lebih serius. Dalam hal ini perawat bertangggung jawab membantu klien memperoleh kembali kesehatan dan kehidupan mandiri yang optimal melalui proses pemulihan dengan biaya, waktu dan tenaga seminimal mungkin. Oleh karena itu perawat harus melakukan perawatan luka yang tepat sesuai perkembangan ilmu pengetahuan dan teknologi (Potter dan Perry, 2009 dalam Naralia, T, 2015).

Perawatan luka merupakan asuhan keseharian perawat di bangsal, terutama pada ruang perawatan medical surgical. Perawat dituntut untuk mempunyai pengetahuan dan keterampilan yang adekuat terkait dengan proses perawatan luka yang dimulai dengan pengkajian komprehensif, perencanaan intervensi yang tepat, implemantasi tindakan, evaluasi hasil yang ditemukan selama perawatan serta hasil dokumentasi hasil yang sistematis (Sinaga, dkk,2012).

Teknik perawatan luka terkini di dunia keperawatan yaitu menggunakan prinsip lembab tertutup, suasana lembab pada luka mendukung terjadinya proses penyembuhan luka (Blackley, 2004 dalam Septiyanti, Maria dkk, 2014). Teknik perawatan luka lembab dan tertutup atau yang dikenal "moist wound healing" adalah metode mempertahankan kelembaban luka dengan menggunakan bahan balutan penahan kelembaban sehingga menyembuhkan luka, pertumbuhan jaringan dapat terjadi secara alami.

Moist wound healing bertujuan untuk mempertahankan isolasi lingkungan luka yang tetap lembab dengan menggunakan balutan penahan kelembaban oklusif dan semi oklusif. Balutan tersebut dapat mempercepat penyembuhan $45 \%$ lebih cepat, mengurangi komplikasi infeksi dan pertumbuhan jaringan parut residual sehingga perawatan luka dapat dioptimalkan Schultz et all, 2007 dalam naralia T, 2015).

Munculnya konsep "moist wound healing"menjadi dasar munculnya pembalut luka modern 
(Mutiara, 2009 dalam Septiyanti, dkk, 2014).

Maibach, Bashir dan McKibbon (2002) dalam Naralia, $T$ (2015), mengatakan metode lembab dengan balutan tertutup secara klinis memiliki keuntungan akan meningkatkan proliferasi dan migrasi dari sel-sel epitel disekitar lapisan air yang tipis, mengurangi resiko infeksi dan timbulnya jaringan parut. Beberapa keunggulan metode ini dibandingkan dengan kondisi luka yang kering adalah meningkatkan re-epitalisasi 30-50\%, meningkatkan sintesa kolagen sebanyak $20-60 \%$, dan rata-rata reepitalisasi dengan kelembaban 2-6 kali lebih cepat dan epitelisasi terjadi 3 hari lebih awal daripada luka yang dibiarkan terbuka dan mengering.

Berdasarkan penelitian terkait oleh Riani, dkk pada tahun 2017 di RSUD Bakinang mengatakan pasien dengan luka diabetik yang mendapatkan perawatan luka diperoleh penurunan skor derajat luka yang cukup besar pada kelompok dengan metode moist wound healing di bandingkan menggunakan $\mathrm{NaCl}$ 0,9\% + madu.

Naralia T (2015) di RSUD H. Adam Malik hasil penelitiannya menunjukkan $50 \%$ perawat yang memiliki pengetahuan cukup tentang perawatan luka dengan menggunakan metode moist wound healing dan $31,7 \%$ responden memiliki pengetahuan yang kurang tentang perawatan luka metode moist wound healing.

Perawatan luka di Rumah Sakit saat ini masih menggunakan metode basah ke kering. Metode tersebut menggunakan kasa yang basah menutupi luka dan kemudian membiarkannya kering pada luka tersebut, dan setelah kering bekas luka atau jaringan matinya bisa dikupas.
Masalah dengan pendekatan ini adalah seiring dengan jaringan mati yang terkelupas, sel-sel pertumbuhan halus dan jaringan granulasi juga berhenti bertumbuh. Hal ini mengakibatkan tidak hanya pertumbuhan jaringan sehat yang terganggu, tetapi juga menimbulkan rasa nyeri yang berlebihan (Kohr, 2011 dalam Naralia, $\mathrm{T}, 2015)$.

Penelitian oleh Sinaga (2012) menyatakan bahwa $100 \%$ perawat di RSUP Dr. djasemen Saragih Pematang Siantar masih menerapkan cara lama dalam perawatan luka yang digunakan dengan teknik basah dan kering, hal ini dapat menyebabkan hipogranulasi dan hipergranulasi, serta mempercepat terjadinya infeksi.

Berdasarkan hasil wawancara awal di RS PMI Aceh Utara terdapat 10 orang perawat, diantaranya di peroleh 6 orang perawat tidak mengetahui teknik perawatan luka menggunakan metode moist wound healing dan 4 orang perawat lainnya mengetahui teknik perawatan luka menggunakan metode moist wound healing. Berdasarkan latar belakang tersebut diatas maka penulis tertarik untuk melakukan penelitian dengan judul "Pengetahuan Perawat Tentang Perawatan Luka Metode Moist Wound Healing di RS PMI Aceh Utara".

\section{METODE PENELITIAN}

Desain penelitian yang digunakan dalam penelitian ini adalah deskriptif yang bertujuan untuk mengetahui pengetahuan perawat tentang perawatan luka metode moist wound healing di RS PMI Aceh Utara. Populasi dalam penelitian ini adalah semua perawat di RS PMI Aceh Utara yang berjumlah 60 orang. Teknik pengambilan sampel yang digunakan dalam penelitian ini adalah purposive sampling yaitu penentuan sampel 


\begin{tabular}{|c|c|c|c|}
\hline $\begin{array}{l}\mathrm{N} \\
\text { o. }\end{array}$ & $\begin{array}{c}\text { Data } \\
\text { Demogr } \\
\text { afi }\end{array}$ & $\begin{array}{c}\text { Frekue } \\
\text { nsi (f) }\end{array}$ & $\begin{array}{c}\text { Persenta } \\
\text { se }(\%)\end{array}$ \\
\hline & Umur & & \\
\hline 1 & $17-25$ & 11 & $30,6 \%$ \\
\hline 2 & tahun & 20 & $55,6 \%$ \\
\hline 3 & $26-35$ & 4 & $11,1 \%$ \\
\hline \multirow[t]{7}{*}{4} & tahun & 1 & $2,8 \%$ \\
\hline & $36-45$ & & \\
\hline & tahun & & \\
\hline & $46-55$ & & \\
\hline & tahun & & \\
\hline & Jenis & & \\
\hline & Kelamin & & \\
\hline 1 & $\mathrm{LK}$ & 10 & $27,8 \%$ \\
\hline \multirow[t]{2}{*}{2} & PR & 26 & $72,2 \%$ \\
\hline & $\begin{array}{l}\text { Pendidik } \\
\text { an }\end{array}$ & & \\
\hline 1 & $\mathrm{Ns}$ & 6 & $16,7 \%$ \\
\hline \multirow[t]{3}{*}{2} & DIII & 30 & $83,3 \%$ \\
\hline & Lama & & \\
\hline & Bekerja & & \\
\hline 1 & $1-5$ & 20 & $55,6 \%$ \\
\hline 2 & tahun & 9 & $25 \%$ \\
\hline \multirow[t]{8}{*}{3} & $6-10$ & 7 & $19,4 \%$ \\
\hline & tahun & & \\
\hline & $11-15$ & & \\
\hline & tahun & & \\
\hline & Pernah & & \\
\hline & Ikut & & \\
\hline & Pelatiha & & \\
\hline & n Luka & & \\
\hline 1 & YA & 4 & $11,1 \%$ \\
\hline \multirow[t]{2}{*}{2} & TIDAK & 32 & $88,9 \%$ \\
\hline & Jumlah & 36 & $100 \%$ \\
\hline
\end{tabular}

dengan pertimbangan khusus sehingga layak dijadikan sampel (Khairani, 2016). Jumlah sampel pada penelitian ini adalah 36 orang perawat yang menangani perawatan luka dengan mengacu pada kriteria inklusi dan eksklusi yang telah ditetapkan

Analisa data yang digunakan pada penelitian ini adalah analisa univariat. Analisa ini dilakukan terhadap tiap variabel dari hasil penelitian. pada umumnya dalam analisis ini hanya menghasilkan distribusi dan persentase dari tiap variabel dengan menggunakan rumus persentase

\section{HASIL PENELITIAN}

Tabel 5.1 Distribusi Frekuensi Responden Berdasarkan Data Demografi di RS PMI Aceh Utara Tahun $2020(\mathrm{n}=36)$

Berdasarkan tabel 5.1 diperoleh bahwa mayoritas umur responden penelitian adalah 26-35 tahun sebanyak 20 responden $(55,5 \%)$ dengan jenis kelamin rata-rata perempuan sebanyak 26 responden $(72,2 \%)$, pendidikan minimal DIII sebanyak 30 responden $(83,3 \%)$, lama bekerja rata-rata responden adalah 1-5 tahun sebanyak 20 responden $(55,6 \%)$ dan yang pernah mengikuti pelatihan perawatan luka sebanyak 4 responden $(11,1 \%)$ dan yang tidak mengikuti pelatihan dari 36 responden yang diteliti.

$\begin{array}{lrr}\text { Tabel } 5.2 \quad \text { Distribusi } & \text { Frekuensi } \\ \text { Pengetahuan } & \text { Perawat } & \text { Tentang } \\ \text { Perawatan Luka Metode Moist Wound } & \text { Mealing di RS PMI Aceh Utara }\end{array}$

\begin{tabular}{lccc}
\hline No & Pengetahua & \multicolumn{2}{c}{ Jumlah } \\
\cline { 3 - 4 }$\cdot$ & $\mathbf{n}$ & $\begin{array}{c}\text { Frekuen } \\
\text { si (f) }\end{array}$ & $\begin{array}{c}\text { Persenta } \\
\text { se (\%) }\end{array}$ \\
\hline 1 & Baik & 6 & $16,7 \%$ \\
2 & Cukup & 19 & $52,8 \%$ \\
3 & Kurang & 11 & $30,6 \%$ \\
\hline & Total & $\mathbf{3 6}$ & $\mathbf{1 0 0 \%}$ \\
\hline
\end{tabular}

Tabel 5.2 diperoleh hasil pengetahuan perawat tentang perawatan luka metode moist wound healing di RS PMI Aceh Utara dalam katagori baik sebanyak 6 responden (16,7\%), katagori cukup sebanyak 19 responden (52,8\%), dan katagori kurang sebanyak 11 responden $(30,5 \%)$. 


\section{PEMBAHASAN}

Data karakteristik responden yang didapat dari hasil penelitian ini diperoleh bahwa mayoritas umur responden peneliti adalah 26-35 tahun sebanyak 20 responden $(55,5 \%)$. Usia dewasa dalam penelitian ini merupakan usia produktif dimana pada usia ini responden akan memusatkan harapanharapannya untuk bersaing dengan responden yang lain atau rekan kerjanya.menurut Ramadhani (2015) semakin bertambahnya usia maka pekerja akan membawa sifat-sifat positif dan melaksanakan pekerjaannya seperti interaksi yang komitmen dalam pekerjaannya. Menurut Hasibuan (2010), umur akan mempengaruhi kondisi fisik, mental, kemampuan kerja dan tanggung jawab seseorang.

Mayoritas responden yang ikut berpartisipasi dalam penelitian ini berjenis kelamin rata-rata perempuan yaitu sebanyak 26 responden $(72,2 \%)$. Hal ini disebabkan karena perawat identik dengan seorang wanita, meskipun dalam kenyataan nya lakilaki juga memiliki hak serta mampu berprofesi sebagai seorang perawat (Sheldon, 2010). Hal ini sejalan dengan pendapat Nilson dan Lasson (2005, dalam Potter dan Perry, 2009) menunjukkan bahwa laki-laki cenderung mengkomunikasikan sesuatu secara langsung tanpa banyak pertimbangan dan melihat hubungan sebagai tugas saja, sedangkan perempuan cenderung lebih berhatihati dan teliti dalam melakukan penilaian terhadap sesuatu yang dianggap baik dengan menggunakan perasaan.

Untuk katagori pendidikan, didapatkan hasil Lebih dari setengah total responden berpendidikan D3 Keperawatan yaitu sebanyak 30 responden $(83,3 \%)$ dan perawat professional (Ners) sebanyak 6 responden $(16,7 \%)$. Pendidikan merupakan salah satu faktor penting yang dapat menambah pengetahuan seseorang, sehingga tingkat pendidikan mendukung pengetahuan yang baik yang dimiliki responden paada penelitian ini. Hal ini didukung oleh pendapat Notoatmodjo (2010) bahwa pendidikan dapat mempengaruhi cara pandang seseorang terhadap informasi baru yang diterimanya. Maka dapat dikatakan bahwa semakin tinggi tingkat pendidikannya, maka semakin mudah seseoarang menerima informasi yang di dapatnya. Hal ini sejalan dengan penelitian Septiyanti (2015), menunjukkan ada peningkatan pengetahuan yang signifikan antara tingkat pengetahuan sebelum dan sesudah diberikan edukasi mengenai perawatan luka lembab tertutup di RS Eka Hospital Pekanbaru.

Pada penelitian ini hampir setengah dari total responden memiliki pengalaman bekerja dalam pelayanan keperawatan yaitu 1-5 tahun sebanyak 20 responden $(55,6 \%)$. Pengalaman merupakan aspek terpenting dalam proses pembelajaran yang dapat berimplikasi positif menambah pengetahuan seseoarang terhadap suatu hal. Sesuai penelitian yang dilakukan oleh Islam (2010), pengalaman kerja 110 tahun dalam keperawatan memiliki tingkat pengetahuan yang jauh lebih baik dibandingkan dengan pengalaman kerja 21-30 tahun. Islam (2010) juga mengatakan bahwa perawat dengan tahun kerja yang lebih lama memiliki kesempatan yang lebih rendah mengupdate ilmunya.

Pada penelitian ini sebanyak 32 responden $(88,9 \%)$ responden terdata belum pernah mengikuti pelatihan tantang perawatan luka dengan metode 
moist wound healing atau perawatan luka modern. Sumber informasi biasanya didapatkan melalui pelatihanpelatihan yang dilakukan. Pelatihan merupakan salah satu sumber informasi yang menjadi perantara dalam menyampaikan informasi, merangsang fikiran dan kemapuan serta menambah pengetahuan (Notoadmodjo,2010). Dari data yang diperoleh beberapa orang responden sudah pernah mengikuti pelatihan selain pelatihan perawatan luka seperti pelatihan Bantuan Hidup Dasar (BHD), Pencegahan dan Penanganan Infeksi (PPI), Keselamatan dan Kesehatan Kerja RS (K3RS). Pelatihan - pelatihan tersebut telah di fasilitasi oleh rumah sakit untuk memenuhi standar akreditasi rumah sakit.

Berdasarkan hasil dari penelitian yang telah dilakukan di RS PMI Aceh Utara menunjukkan sebanyak 6 responden $(16,7 \%)$ memiliki pengethaun baik, 19 responden $\quad(52,8 \%)$ memiliki pengetahuan yang cukup dan 11 responden $(30,5 \%)$ memilki pengetahuan kurang tentang perawatan luka dengan metode moist wound healing.

Pada penelitian sebanyak 36 orang $(100 \%)$ responden mampu menjawab kuisioner nomor urut 1 mengenai prinsip moist wound healing bahwa prinsip moist wound healing adalah lembab tertutup. McKibbon (2002) dalam Naralia $T$ (2015) mengatakan bahwa metode perawatan liuka secara lembab dengan balutan tertutup secara klinis memiliki keuntungan akan meningkatkan proliferasi dan migrasi dari sel-sel epitel disekitar lapisan air yang tipis serta mengurangi resiko infeksi dan timbulnya jaringan parut.
Sebanyak 28 responden $(77,8 \%)$ responden sudah mengetahui tentang pemilihan balutan yang tepat guna mendukung metode perawatan luka lembabyaitu balutan yang mampu mencegah infeksi, menampung eksudat, tertutup rapat dan dapat mempertahankan kelembaban lingkungan luka untuk mendukung proses penyembuhan luka. Menurut Arisanty (2012), mengatakan bahwa balutan oclisive ataupun semiocclusive mampu menggantikan fungsi kulit yang hilang atau rusak, mempertahankan kelembababan, mengoptimalkan proses debris, mencegah trauma atau perdarahan berulang, mengefektifkan biaya, waktu dan tenaga karena balutan modern tidak perlu diganti setiap hari.

Mayoritas responden memiliki pengetahuan yang baik tentang teknik pencucian luka yang tepat tanpa menyebabkan trauma berulang yaitu sebanyak 30 responden $(83,3 \%)$ responden telah mengetahui bahwa showering (mengirigasi) merupakan teknik pencucian yang tepat tanpa mengakibatkan trauma dan perdarahan berulang pada luka. Beberapa teknik pencucian luka lainnya seperti swabbing (menggosok) tidak dianjurkan dapa luka dengan banyak vaskularisasi karena dapat menyebabkan perdarahan dan trauma berulang sehingga dapat meningkatkan resiko inflamasi pada jaringan yang sedang mengalami granulasi dan memperlama proses penyembuhan luka (Gitarja, 2008).

Sebanyak 30 responden $(83,3 \%)$ responden sudah sangat mengetahui tentang tipe cairan pencuci luka yang tepat dan mendukung perawatan luka dengan menggunakan metode moist wound healing. Mayoritas responden sudah 
mengetahui bahwa $\mathrm{NaCl} \quad 0,9 \quad \%$ merupakan tipe cairan pencuci luka yang baik. Menurut pedoman AHCPR (1994 dalam Naralia T (2015)) mengatakan bahwa cairan cairan pembersih yng dianjyrkan adalah normal salin (sodium klorida). Sodium klorida atau Natrium Klorida tersusun atas $\mathrm{Na}$ dan $\mathrm{Cl}$ memiliki komposisi yang sama dengan plasma darah maka dengan demikian cairan tersebut aman bagi tubuh (Morison, 2013).

Hasil penelitian juga menunjukkan sebanyak 24 responden $(66,7 \%)$ dari total responden mengetahui tentang autolisis debridement. Menurut Maryunani (2013), autolisis debridement merupakan proses peluruhan jaringan nekrotik oleh tubuh sendiri dengan syarat lingkungan harus lembab. Sebuah penelitian yang dilakukan oleh Mwipatayi pada tahun 2004 pada 10 orang pasien dengan luka kronik dengan jaringan nekrotik, dua diantaranya dilakukan proses autolisis debridement menggunakan balutan polyacrylate mengalami penurunan luas area luka dari $26,4 \mathrm{~cm}^{2}$ menjadi $21,4 \mathrm{~cm}^{2}$ dalam waktu 5 hari. Sedangkan delapan orang pasien lainnya dirawat menggunakan balutan basah kering mengalami penurunan luas rea luka dari $25 \mathrm{~cm}^{2}$ menjadi $23^{2}$ dalam waktu 5 hari. Dari hasil penelitian yang dilakukan oleh Mwpatayi (2004) menunjukkan bahwa proses autolisis debridement lebih efektif terhadap perawatan luka.

Untuk kuisioner yang memiliki jumlah jawaban yang benar yang sangat sedikit dari responden adalah kuisioner no urut 20 hanya 8 responden $(22,2 \%)$ perawat yang mengetahui bahwa jenis balutan ideal untuk luka dengan yang banyak mengeluarkan cairan eksudat adalah balutan alginate.
Kabanyakan dari total responden belum menenal jenis-jenis balutan primer maupun sekunder yang sesuai dengan jenis luka dengan karakteristik tertentu. Asumsi peneliti bahwa ketidaktahuan responden tersebut disebabkan karena mayoritas responden masih menggunakan jenis balutan yang sama untuk berbagai jenis luka dengan karakeristik luka yang berbeda. Balutan oclusisive modern memiliki harga yang lebih mahal dari balutan konvensional, kelebihan dari balutan occlusive modern adalah dapat mengurangi frekuensi penggantian balutan serta dapat meningkatkan kecepatan penyembuhan dengan prinsip lembab tertutup sehingga dapat menghemat biaya yang dibutuhkan untuk perawatan luka (Schuiitz et al., 2005). Sesuai dengan penelitian yang dilakukan oleh Ohura, Hiromi dan Yosio pada tahun 2004 tentang efektifitas pengeluaran biaya pada perawatan luka dengan balutan tradisional dan balutan modern. Hasil dari penelitian nya mengungkapkan bahwa total biaya yang digunakan selama 12 minggu untuk perawatan luka dengan luka derajat II dan III menunjukkan hasil pengeluaran biaya yang berbeda yakni rata-rata biaya yang dikeluarkan pada perawatan luka dengan menggunakan balutan modern dengan prinsip moist wound healing yaitu sebesar 87,715 yen, jumlah tersebut lebih rendah nominalnya dibandingkan perawatan luka dengan dengan balutan tradisional dengan menggunakan kassa yaitu sebesar 131,283 yen.

Hasil penelitian menunjukkan hanya 17 responden $(47,2 \%)$ responden yang mengetahui prosedur pengkajian luka yang tepat. Sebagian besar dari mereka mengatakan bahwa pengkajian luka dilakukan sebelum 
luka tersebut dibersihkan. Apabila pengkajian luka dilakukan sebelum luka dibersihkan maka benda asing yang ada disekitar luka akan menghambat penilaina derajat luka yang dialami. Warna dasar luka akan terhalangi oleh benda asing yang berada diatas permukaan luka. Menurut Marison (2013), pengkajian luka harus dilakukan setelah luka dibersihkan untuk dapat menentukan hasil pengkajian dan intervensi yang akurat.

$$
\text { Hasil penelitian juga }
$$
menujukkan hanya 13 responden $(36,1 \%)$ dari total responden yang mengetahui tujuan kelembaban yang seimbang (moisture balance) pada prinsip (TIME) dalam perawatan luka metode terttutup yakni melindungi luka dari trauma saat mengganti balutan luka dan melindungi kulit di sekitar luka.

Hal ini dapat disimpulkan bahwa pengetahuan responden tentang perawatan luka dengan metode moist wound healing tergolong masih rendah karena data menunjukkan mayoritas responden memilki pengetahuan cukup dan kurang. Penelitian yang sama juga pernah dilakukan oleh Naralia T (2015) menunjukkan $50 \%$ perawat yang berkerja di ruang bedah RSUD $\mathrm{H}$. Adam Malik memiliki pengetahuan yang cukup tentang perawatan luka metode lembab tertutup.

Dari pembahasan diatas menunjukkan bahwa sebanyak 19 responden $\quad(52,8 \%) \quad$ memiliki pengetahuan cukup tentang perawatan luka metode moist wound healing. Tingkat pengetahuan yang cukup masih perlu ditingkatkan menjadi pengetahuan yang baik karena akan mendukung terciptanya pelayanan yang baik pula.
Asumsi peneliti bahwa pengetahuan perawat untuk katagori baik, dapat dipengaruhi oleh banyak hal seperti usia, pendidikan, lama berkrja dan pelatihan. Usia dewasa dalam penelitian ini merupakan usia produktif dimana pada usia ini responden akan memusatkan harapan-harapan nya unuk bersaing dengan responden yang lain atau rekan kerjanya. Peneliti juga beranggapan bahwa dukungan dari rumah sakit sangat penting untuk meningkatkan pengetahuan perawat dengan memberikan kesempatan atau menfasilitasi perawat dengan mengadakan seminar dan pelatihan tentang perawatan luka. Hal ini sejalan dengan yang dilakukan oleh Nursanty (2020) di RS PKU Muhammadiyah Bantul hasil penelitiannya menunjukkan bahwa perawat yang telah mengikuti pelatihan perawatan luka pasca operasi efektif terhadap penerapan SOP perawatan luka bersih oleh perawat di Instalasi Rawat Inap RS PKU Muhammadiyah Bantul.

\section{KESIMPULAN DAN SARAN}

\section{Kesimpulan}

Berdasarkan hasil dari penelitian yang telah dilakukan, peneliti dapat menarik kesimpulan bahwa perawat PMI Aceh utara memiliki pengetahuan yang cukup tentang perawatan luka metode moist wound healing yaitu sebanyak $52,8 \%$, perawat yang memiliki pengetahan yang baik sebanyak 16,7\%, dan perawat yang memiliki pengetahuan yang kurang sebanyak $30,5 \%$.

Hal ini dapat disimpulkan bahwa pengetahuan perawat tentang perawatan luka dengan metode moist wound healing tergolong masih rendah karena data menunjukkan mayoritas 
responden memilki pengetahuan cukup dan kurang

\section{Saran}

Kepada responden diharapkan dapat menambah pengetahuan dalam tindakan perawatan luka metode moist wound healing.

Kepada tempat penelitian diharapkan hasil penelitian ini dapat memberikan gambaran mengenai pengetahuan perawat tentang perawatan luka metode moist wound healing di RS PMI Aceh Utara. Melalui hasil penelitian ini disarankan bagi pihak RS PMI Aceh Utara agar dapat menfasilitasi pelatihan perawatan luka pada perawat. Hasil data demografi dan wawancara responden menunjukkan bahwa sebagian besar perawat belum pernah mendapatkan pelatihan perawatan luka dari rumah sakit. Hal tersebut yang menyebabkan masih banyak perawat yang memiliki pengetahuan yang cukup tentang perawatn luka metode moist wound healing.

Kepada institusi pendidikan diharapkan hasil penelitian ini menjadi referensi bagi mahasiswa dalam mengembangkan ilmu keperawatan serta memberi informasi tentang Gambaran Tingkat Pengetahuan Perawat Tentang Perawatan Luka Metode Moist Wound Healing.

Bagi peneliti selanjutnya diharapkan perlu kiranya untuk dilakukan penelitian lain yang lebih mendalam tidak hanya mengenai pengetahuan perawat tentang perawatan luka namun juga mencakup sikap dan aplikasi tindakan perawatan luka di rumah sakit tertentu.

\section{DAFTAR PUSTAKA}

Arikunto, S. (2010). Prosedur Penelitian Suatu Pendekatan Praktik. Jakarta : PT. Rineka Cipta.

Arisanty, Irma. P. (2013). Konsep Dasar Manajemen

Keperawatan Luka . Jakarta: Mitra Wacana Medika.

Ekaputra, E. (2013). Evolusi Manajemen Luka : Menguak 5 Keajaiban Moist Dressing . Jakarta : Trans Info Media.

Hasibuan. (2013). Organisasi Dan Motivasi Peningkatan Aktivitas. Jakarta : Bumi Aksara.

Islam, M.S. (2010). Nurses' Knowledge, Attitude, And Practice Regarding Pressure Ulcer Prevention For Hospitalized Patients At Rajshahi Medical College Hospital In Bangladesh. Thesis For The Degree Of Master Of Nursing Science. Thailand: Prince Of Songkla University.

Machfoedz. (2010). Metodelogi Penelitian. Yogyakarta : Fitramaya.

Maghfuri, Ali. (2016). Perawatan Luka Diabetes Melitus. Jakarta : Salemba Medika.

Maibach, Bashir. (2002). Efidence Based Dermatology. Canada : Bc Decker.

Marisson, M.J. (2013). Manajemen Luka. Jakarta :EGC. 
Mwapatayi et al. (2005). Clinic Experience - With Activated Polyacrylate Dressing (Tenderwet 24). Journal of Royal Perth Hospital Australia, Vol :13, No, 2

Maryunani, A. (2013). Perawatan Luka Modern Praktis Pada Wanita Dengan Luka Diabetes. Jakarta : Trans Info Media.

Muntoha, Ragil (2016) Hubungan Beban Kerja Dengan Perilaku Caring Perawat. Universitas Padjajaran.

Naralia, T.W. (2015). Pengetahuan Perawat Tentang Perawatan Luka Dengan Metode Moist Wound Healing di RSUD $H$. Adam Malik Medan. Jurnal of Talentaconference series:Topical Medicine (TM). 10.32734

Notoatmodjo, S. (2010). Metodologi Penelitian Kesehatan. Jakarta : Rineka Cipta.

Nursanty,Oci E dkk (2020).Penerapan Standar Operasional Prosedur Perawatan Luka Bersih Melalui Pelatihan Pasca Operasi.Universitas Muhammadiyah Yogyakarta.Jurnal ilmiah kesehatan.1412-2804.

Potter dan Perry. (2009). Fundamental Keperawatan (Edisi) 7. Jakarta : Salemba Medika.

Prasetyono, Theddeus. (2016). Panduan Klinis Manajemen Luka. Jakarta: EGC.
Ramadhani. (2015). Analisis FaktorFaktor Yang Mempengaruhi Kepuasan Kerja Perawat. Universitas Riau.

Riani,dkk. (2017). Perbandingan Efektifitas Perawatan Luka Modern "Moist Wound Healing" Dan Terapi Komplementer "Nacl 0,9\% + Madu Asli" Terhadap Penyembuhan Luka Kaki Diabetik Derajat II di RSUD Bakinang. Universitas Pahlawan Tuanku Tambusai. journal.universitaspahlawan.ac. id.

Septiyanti, Maria. et al. (2014). Hubungan Tingkat Pengetahuan Dengan Sikap Perawat Tentang Perawatan Luka Diabetes Dengan Menggunakan Teknik Moist Wound Healing. Program Studi Ilmu Keperawatan Universitas Riau.

Journal.Unair.ac.id.2620-7478

Schultz et al. (2005). Wound Healing And TIME; New Concept And Scientific Application : Wound Repair And Regeneratiaon

Sinaga, M. (2012). Gambaran Penggunaan Bahan Pada Perawatan Luka di RSUD Dr. Djasamen Saragih Pematangsiantar. Medan : Fakultas Keperawatan USU. repository.usu.ac.id.

Sheldon. (2010). Komunikasi Keperawatan Berbicara Dengan Pasien. Jakarta: Erlangga. 
Sudjana. (2002). Metode Statistil, Edisi

6. Bandung : Tarsito.

Sulistyaningsih. (2012). Metodelogi Penelitian KuantitatifKualitatif. Yogyakarta : Graha Ilmu.

White, Dr. Barry. (2009). National Best Practice And Evidence Based Guidelines For Wound Management. Irland : Health Service Executive
Wound Care Center, (2012). Buku Panduan Pelatihan Perawatan Luka : Certified Wound Care Clinician Associate. Edisi 1. Bogor : CWCCAP.

WoundsWest Wound Prevalence Survey. (2013). State-Wide Overview Report health.wa.gov.au 